\title{
PERAN PUBLIC RELATIONS INTERNAL DALAM PENGENDALIAN MUTU PERUSAHAAN (STUDI KASUS DI PT. JALAN TOL LINGKAR LUAR JAKARTA)
}

\author{
Kevin Danu Prasetya ${ }^{1}$ dan Kusumajanti ${ }^{2}$ \\ ${ }^{1,2}$ Program Studi IImu Komunikasi, UPN Veteran Jakarta
}

Naskah diterima tanggal 26-11-2019, direvisi tanggal 27-11-2019, disetujui tanggal 30-11-2019

\begin{abstract}
Abstrak. Penelitian ini membahas tentang sejauh mana peran public relations internal dalam PT. Jalan Tol Lingkarluar Jakarta dalam menjalankan proses pengendalian mutu perusahaan. Tujuannya adalah untuk mengetahui sejauh mana PT. Jalan Tol Lingkarluar Jakarta dalam menjalankan pengendalian mutu perusahaan. Metode penelitian yang digunakan adalah metode penelitian studi kasus dengan pendekatan kualitatif. Teknik pengumpulan data yang di gunakan berdasarkan wawancara mendalam secara langsung dengan ketua manajemen representative PT. jalan Tol Lingkarlua Jakarta, staff manajemen representative PT. jalan Tol Lingkarlua Jakarta serta 2 orang informan yang merupakan perwakilan dari devisi-devisi yang mengikuti proses pengendalian mutu PT. jalan Tol Lingkarluar Jakarta. Hasil penelitian menunjukan bahwa peran public relations dalam menjalankan pengendalian mutu perusahaan sudah cuku sesuai dan berjalan sebagaimana mestinya, walaupun dalam eksekusinya masih ada kendala yang dihadapi. Dapat dikatakan public relations internal PT. Jalan Tol Lingkarluar Jakarta telah menjalankan tugasnya denga baik bersama dengan devisi-devisi terkait. Sehingga perlahanlahan kedepannya mungkin dapat ditingkatkan lagi rasa kepedulian dalam menjaga citra perusahaan PT.Jalan Tol lingkarluar Jakarta serta semakin responsif terhadap apa yang sedang diperlukan masyarakat khususnya pengguna jalan tol PT. Jalan Tol Lingkarluar Jakarta demi menciptakan ide-ide baru.
\end{abstract}

Kata Kunci : PT. Jalan Tol Lingkarluar Jakarta, Peran Public Relations internal, pengendalian mutu perusahaan

Abstract. This study discusses the extent of the role of internal public relations in PT. Jakarta Outer Ring Road Toll Road in carrying out the company's quality control process. The aim is to find out the extent of PT. Jakarta Outer Ring Road Toll Road in carrying out company quality control. The research method used is a case study research method with a qualitative approach. Data collection techniques used are based on in-depth interviews directly with the chairman of the management representative of PT. Jalan Tol Lingkua Jakarta, staff management representative of PT. Jakarta Lingkarlua Toll Road and 2 informants representing representatives of the divisions following the quality control process of PT. Jakarta Ring Road Toll Road. The results showed that the role of public relations in carrying out company quality control was sufficiently appropriate and running as it should, even though in its execution there were still obstacles encountered. It can be said that PT. The Jakarta Outer Ring Road Toll has carried out its duties well together with the related divisions. So that slowly in the future it might be possible to increase the sense of care in maintaining the corporate image of PT. Jalan Tol Outer Jakarta and be more responsive to what is needed by the public especially PT. Jakarta Outer Ring Road Toll Road for the sake of creating new ideas.

Keywords: PT. Jakarta Outer Ring Road Toll Road, Role of Internal Public Relations, Company Quality Control 


\section{PENDAHULUAN}

PT. Jalan Tol Lingkarluar Jakarta adalah merupakan dari anak perusahaan PT. Jasa Marga (persero) Tbk yang berdiri pada akhir tahun 2000 tepatnya pada tanggal 22 desember tahun 2000 yang bergerak dibidang jasa Manajemen Layanan Transaksi, Manajemen Layanan Lalu Lintas serta Manajemen Layanan Pemeliharaan Jalan Tol. Berawal mulanya berdiri PT. Jalan Tol Lingkarluar Jakarta dipercaya oleh PT. Jasa Marga (persero) Tbk, untuk mengoperasikan Jalan Tol yang berada di Lingkar luar Jakarta atau bisa dikatakan jalan tol yang tidak melintas didalam kota Jakarta melainkan diluar kota Jakarta tepatnya dipinggir kota Jakarta. PT. Jalan Tol Lingkarluar Jakarta dipercaya untuk mengoperasikan Jalan Tol LingkarLuar Jakarta sepanjang 45 kilometer yang mengelilingi kota Jakarta dari UlujamiPondok Pinang-TMII Junction- Cikunir- Cakung sampai dengan Rorotan.

Sebagai bukti nyata komitmen PT.Jalan Tol Lingkarluar Jakarta untuk meningkatkan mutu pelayanan terhadap publik yang menggunakan jasanya, PT. Jalan Tol Lingkarluar Jakarta selalu berusaha untuk memberikan fasilitas-fasilitas terbaik yang didapat dari kepuasan dan masukan serta saran dari masyarakat pengguna jalan tol. Tentunya hal ini dapat menjadikan fasilitas yang diinginkan oleh masyarakat pengguna jalan tol sesuai dengan kebutuhan di zaman sekarang dimana semuanya diharapkan bisa lebih mudah, efektif dan efisien. Di era globalisasi sekarang, masyarakat di hadapkan dengan adanya berbagai macam fasilitas yang ada di berbagai perusahaan yang sedang tumbuh dan berkembang, Sehingga banyak sekali perusahaan yang berkompetisi untuk menarik perhatian masyarakat. Agar fasilitas yang disediakan dapat digunakan dengan maksimal oleh masyarakat dan juga berbagai macam inovasi baru yang di rancang oleh pihak perusahaan diharapkan bisa menjadi yang terbaik di mata masyarakat luas.

Oleh karena itu peneliti tertarik dengan bagaimana perusahaan yang memperhatikan standart mutu perusahaan khususnya di PT Jalan Tol Lingkarluar Jakarta untuk menjaga citra dan reputasi perusahaan karena perusahaan yang beroperasi dibidang pelayanan jalan tol harus total dalam menyediakan pelayanan jasa dan produk yang memuaskan.

Banyak cara yang di lakukan oleh instansi di perusahaan supaya menjadi salah satu perusahaan terbaik, diantaranya adalah dengan meningkatkan mutu perusahaan, karena ketika kahalayak banyak khususnya pengguna jalan tol mendatangi suatu perusahaan, maka hal pertama yang mereka lihat adalah standart mutu perusahaannya. Oleh karena itu mutu perusahaan jangan di anggap tidak penting karena salah satu pondasi dari sebuah perusahaan adalah mutu terbaik yang di sediakan dari perusahaan tersebut.

Lewat jalur komunikasi yang di bangun oleh Public Relations internal di PT. Jalan Tol Lingkarluar Jakarta sebagai komitmen dari sebuah manajemen yang baik dapat membantu membangun memuculkan kerjasama, pemahaman antara divisi internal dan eksternalnya, yang melibatkan manajemen dan isu, mambantu manajemen untuk terus memeberikan informasi dan tanggap terhadap opini public, mendefinisian serta menekan tanggung jawab manajemen untuk memeberikan pelayanan terbaik untuk kepentingan umum, membantu manajemen untuk tetap mengkuti dan memanfaatkan perubahan secara efektif, melayani sebagai system peringatan dini untuk membantu kecendrenguan negative dan menggunakan penelitian yang sehat serta etika komunikasi sebagai hal utama yang diperhatikan. Public Relations internal juga di sebut sebagai manajemen komunikasi antara organisasi dan publiknya.

Public Relations internal juga berfungsi sebagai wadah karyawan untuk mengembangkan inovasi mereka dalam menjalankan pengendalian mutu di perusahaan. Peran public relations internal itu bisa di artikan juga sebagai penyambung komunikasi antar karyawan (employee relations). Public Relations internal juga harus mampu membina hubungan yang baik dengan para pemegang saham di PT. Jalan Tol Lingkarlua Jakarta dan para jajaran direksi di perusahaan, dan mampu memberikan informasi tentang apa yang terjadi dalam organisasi/perusahaan. Karena sebagai pemilik saham, mereka harus selalu tahu perkembangan dan pertumbuhan perusahaan secara transparan agar dapat meningkatkan kepercayaan mereka terhadap perusahaan. Dengan demikian tuntutan yang di berikan dalam menjalankan pengendalian mutu dapat berjalan dengan baik sesuai dengan yang di harapkan oleh pemegang saham dan para petinggi yang ada di perusahaan. 
Memberikan sebuah standard pelayanan ataupun masalah di jalan tol tersebut harus di lakukan dengan baik oleh seorang public relations internal. Membangun sebuah strategi pengendalian mutu perusahaan sangatlah penting dilakukan oleh instansi agar dapat mengetahui apa yang di butuhkan masyarakat dalam kehidupan sehari-hari. Inilah yang di lakukan oleh berbagai perusahaan jalan tol diseluruh Indonesia. Standard untuk menjaga mutu perusahaan bahkan juga menjadi syarat utama agar produk tersebut diakui secara internasional. Oleh karena itu, apabila sebuah perusahaan di Indonesia akan melakukan penjualan produk atau jasa yang dihasilkan, maka sistem penjagaan mutu wajib untuk dilakukan oleh setiap perusahaan. Bukan hanya sebagai syarat, namun juga sebagai langkah yang tepat untuk meningkatkan dan menjaga mutu perusahaan tersebut. Bukan merupakan sebuah hal yang mudah, namun menjadi wajib untuk perusahaan penuhi apabila ingin menjaga mutu sebuah perusahaan. Jangan melupakan bahwa mutu dari mutu perusahaan yang dihasilkan dapat menjadi dasar untuk kemajuan perusahaan yang bersangkutan. Telah semakin diakui mengenai pentingnya sistem manajemen mutu sebagai pondasi dasar sebuah perusahaan dan menjadi sebuah langkah awal untuk mendapatkan pengakuan terhadap berbagai produk dan jasa yang dihasilkan. Perusahaan yang tidak melakukan pengendalian mutu secara optimal maka perusahaan tersebut akan mendapatkan dampak yang signifikan,seperti produk atau jasa yang di berikan setiap tahunnya akan terasa datar dan akan berdampak kepada complain dari konsumen.

Mutu perusahaan di lakukan juga sebagai bentuk suatu dalam menjaga kepuasan konsumen.Dalam hal ini kepuasan konsumen menjadi tujuan utama mengapa mutu sebuah perusahaan harus di lakukan. Dengan melaksanakan pengendalian mutu perusahaan, maka akan muncul ketersediaan data teknik dan teknis mengembangkan inovasi mutu perusahaan, serta disempurnakan dengan desain dan metode yang sudah di tetapkan. Jika sistem kontrol dalam menjalankan pengendalian mutu perusahaan secara efektif, maka kinerja karyawan juga akan meningkat. Hal ini dipengaruhi oleh semangat yang muncul dari para karyawan yang terus mencoba meningkatkan inovasi-inovasi yang berkualitas. Pengendalian kualitas mutu juga bertujuan untuk dapat mempengaruhi suasana pekerjaan yang lebih baik melalui semangat kinerja karyawan yang lebih tinggi. Akibatnya, hubungan antara atasan dan karyawan menjadi lebih baik dan berkelanjutan.

\section{Pendekatan Penelitian}

\section{METODE PENELITIAN}

Pendekatan yang digunakan penulis dalam penelitian melalui pendekatan studi kasus. studi kasus adalah suatu inkuiri empiris yang menyelidiki fenomena di dalam konteks kehidupan nyata, apabila batas-batas antara fenomena dan konteks tidak tampak secara tegas atau jelas dan menggunakan berbagai sumber atau multi sumber bukti. Studi kasus memungkinkan peneliti untuk mempertahankan karakteristik holistik dan bermakna dari peristiwa-peristiwa kehidupan nyata seperti silklus kehidupan seseorang, proses-proses organisasional dan manajerial, perubahan lingkungan sosial, hubungan-hubungan internasional, dan kematangan industri-industri. Penelitian studi kasus dapat dibedakan menjadi tiga tipe, masing-masing adalah tipe eksplanatoris yaitu untuk menjelaskan hubungan kausal dalam konteks kehidupan nyata, tipe eksploratoris yaitu digunakan untuk mengeksplorasi suatu situasi yang tidak dapat dievaluasi secara intevensi atau berdasarkan single point saja, dan tipe berikutnya adalah deskriptif digunakan untuk mendeskripsikan fenomena yang terjadi pada kehidupan nyata.

Studi kasus dikehendaki untuk melacak peristiwa-peristiwa kontemporer, bila peristiwaperistiwa yang bersangkutan tak dapat dimanipulasi. Karena itu studi kasus mendasarkan diri pada teknik-teknik yang lazim digunakan pada strategi historis seperti peneliti sangat bergantung pada dokumen-dokumen primer, dokumen sekunder, peralatan-peralatan budaya, dan fisik sebagai bukti tetapi kemudian menambahkan dua sumber bukti yang biasanya tidak dimiliki oleh penelitian historis yakni observasi dan wawancara sistematik. Dengan demikian kekuatan unik dari studi kasus adalah kemampuannya untuk berhubungan sepenuhnya dengan berbagai jenis bukti, selebihnya dalam beberapa situasi seperti observasi partisipan, 
manipulasi informasi juga dapat terjadi (Robert.K.Yin, 2011:38). Berdasarkan uraian diatas, studi kasus menurut penulis adalah pendekatan yang paling sesuai. Penulis dapat menggali pengalaman subjek penelitian secara mendalam dan kompleks untuk memahami masalah yang terjadi serta meningkatkan kualitas data.

\section{Jenis Penelitian}

Penelitian ini menggunakan jenis penelitian deskriptif kualitatif dengan pendekatan studi kasus. Penelitian kualitatif adalah model pendekatan penelitian yang mengutamakan pada kualitas data. Pertimbangan peneliti dalam memilih metode penelitian kualitatif adalah karena metode ini membahas secara mendalam untuk lebih mengetahui cara pandang objek penelitian ang lebih mendalam melalui berbagai aspek seperti opini, sikap, perilaku, tanggapan baik dari individu maupun kelompok. Selain dimaksudkan mampu menjelaskan studi kasus yang berada di PT.Jalan Tol Lingkarluar Jakarta dengan sedalam-dalamnya melalui pengumpulan data yang diperoleh saat tiba di lapangan.

Penelitian kualitatif adalah metode penelitian yang digunakan untuk meneliti pada kondisi objek yang alamiah dimana peneliti adalah sebagai instrument kunci, teknik pengumpilan data dilakukan secara triangulasi, analisis data bersifat induktif dan hasil penelitian kualitatif lebih menekankan makna daripada generalisasi (Sugiyono, 2009: hlm. 1). Berdasarkan definisi yang dijelaskan di atas, alasan peneliti dalam memilih metode penelitian kualitatif karena ingin menggali informasi lebih dalam mengenai Peran Public Relations PT.Jalan Tol Lingkarluar Jakarta dalam menjalankan konsep atau cara kerja pengendalian mutu.

\section{Metode Pengumpulan Data}

Metode pengumpulan data adalah cara atau teknik bagaimana data itu bisa ditemukan, digali, dikumpulkan, dikategorikan dan dianalisis. Sedangkan instrument pengumpulan data adalah alat yang digunakan untuk mengukur data yang hendak dikumpulkan. Data yang dikumpulkan dalam penelitian ini terdiri dari dua sumber, data-data tersebut adalah sebagai berikut:

\section{Data Primer}

Data primer adalah data penelitian yang berupa informasi tentang variable-variabel penelitian yang diperoleh secara langsung dari sumbernya. Data primer terdiri dari:

a. Wawancara Mendalam

wawancara mendalam adalah suatu teknik metode penelitian kualitatif, dimana seorang responden atau kelompok responden mengkomunikasikan bahan-bahan dan mendorong untuk didiskusikan secara bebas. Dengan wawancara mendalam kepada key informan dan informan, Peneliti dapat mengetahui alasan yang sebenarnya dari responden mengambil keputusan seperti itu. (Ardianto, 2010 : 61). Tujuan dari wawancara ini adalah untuk memperoleh keterangan informasi yang sesuai dengan maksud penelitian. Dalam penelitian ini, dilakukan wawancara mendalam dengan ketua Manajemen Representatif dan Public Relations di PT.Jalan Tol Lingkarluar Jakarta sebagai key informan memperoleh keterangan sesuai dengan permasalahan penelitian.

\section{b. Observasi}

Observasi adalah teknik pengumpulan data yang mempunyai ciri spesifik bila dibandingkan dengan teknik lain. Observasi tidak terbatas pada orang lain, tetapi juga objekobjek alam yang lain (Sugiyono, 2009 : 144). Peneliti melakukan observasi karena pengamatan dilakukan secara non-participant melalui web yang dimilik oleh PT.Jalan Tol Lingkarluar Jakarta.

\section{Data Sekunder}

Data sekunder adalah data yang mendukung dan melengkapi data primer seperti data yang didapatkan dari buku berupa materi tentang konsep teori yang berkaitan dengan penelitian. Selain itu peneliti juga memperoleh data sekunder dari laporan pengguna jalan tol melalui mengisi lembaran formulir yang sudah disediakan yang biasa disebut dengan (corrective preventive action request)oleh pihak PT.Jalan Tol Lingkarluar Jakarta. 


\section{Penentuan Key Informan dan Informan}

Penentuan Key Informan dalam penelitian ini berdasarkan karakteristik yang sesuai dengan tujuan penelitian dan merupakan sumber informasi yang utama karena mengetahui banyak informasi tentang penelitian yang sedang dilakukan. Daymon dan Holloway (2008, hlm : 207), pilihlah Key Informan dengan guna memastikan guna bahwa narasumber tersebut cukup representative (mewakili populasi atau kelompoknya) dan sebuah berdiam lama dalam kelompok tersebut, sehingga memiliki pengetahuan lebih menyangkut aturan, rutinitas dan bahasa dalam kelompoknya.

\section{Teknik Analisis Data}

Peneliti menggunakan analisis data kualitatif. Analisis kualitatif pada penelitian ini adalah menurut konsep Miles dan Huberman. Miles dan Huberman berpendapat bahwa aktivitas dalam analisis data kualitatif dilakukan secara interaktif dan berlangsung secara terus menerus sehingga data yang diperlukan sesuai (Sugiyono, 2009: hlm. 91).

\section{Teknik Keabsahan Data}

Salah satu teknik yang dapat digunakan untuk keabsahan data adalah teknik triangulasi. Menurut Moleong (2014:330), Triangulasi adalah teknik pemerikasaan keabsahan data yang memanfaatkan sesuatu yang lain. Dalam penelitian ini, peneliti menggunakan tringulasi sumber. Triangulasi sumber adalah bentuk triangulasi dengan menggunakan berbagai sumber data, seperti mengumpulkan data dari perusahaan, hasil observasi dan hasil wawancara kepada lebih dari satu subjek yang dianggap memiliki sudut pandang yang berbeda. Pada penelitian ini, triangulasi sumber yang digunakan adalah dengan cara meakukan observasi non participant pada pengguna jalan tol yang memberi keluhan melalui formulir yang sudah disediakan mengenai permasalahan yang ada di lapangan jalan tol). Selain itupeneliti juga melakukan observasi non participant pada media-media yang sudah di sediakan oleh PT.Jalan Tol Lingkarluar Jakarta seperti, formulir CPAR dan web perusahaan serta melakukan wawancara dengan Key Informan dan Informan. Key Informan dan Informan yang peneliti tetapkan berdasarkan karakteristik yang memenuhi dari penelitian ini dan diharapkan dapat sesuai dengan pokok permasalahan penelitian.

\section{HASIL PENELITIAN DAN PEMBAHASAN}

Untuk mengetahui data yang akan dijadikan sebuah penelitian maka membutuhkan informasi yang bisa dijadikan data awal atupun data pendukung untuk melengkapi sebuah penelitian. Dalam memulai penelitian yang berjudul "Peran Public Relations Internal Dalam Pengendalian Mutu Perusahaan (studi kasus di PT.Jalan Tol Lingkarluar Jakarta)", pada tahap awal peneliti melakukan observasi awal untuk mencari data agar peneliti dapat memahami dan memilah informasi apa yang akan peneliti gunakan.

Peneliti melakukan observasi awal yang bermula dari peneliti menyadari bahwa fenomena mutu perusahaan di PT. Jalan Tol Lingkarluar Jakarta memiliki kelebihan dan kelemahan dalam menjalankan pengendalian mutu perusahaan. Berawal dari tujuan yang dimiliki perusahaan yangberhubungan dengan fokus terhadap kepuasan pelanggan.

Kepuasan pelanggan adalah fokus perusahaan demi menjaga citra dan reputasi perushaan. Oleh karena itu PT. Jalan Tol Lingkarluar Jakarta menyediakan formuli aduan yang biasa disebut dengan formulir CPAR (cooperative, pollution, abatement, and research). Formulir CPAR berfungsi sebagai surat aduan pelanggan jalan tol terhadap keluhan yang mereka alami. Keluhan yang diajukan melalui formulir CPAR akan ditindak lanjuti oleh perusahaan apabila masalah yang diajukan membutuhkan proses lama maka akan menjadi proses pengendalian mutu perusahaan.

Peneliti melihat bahwa adanya fenomena tersebut dilatarbelakangi adanya ketidakpuasan yang dirasakan masyarakat khususnya pengguna jalan tol lingkar luar jakarta seperti komplen tehadap pembayaran yang dilakukan secara elektronik terkadang masih sulit untuk dilakukan. Maka dari itu permasalahan-permasalahan yang terjadi di jalan tol dapat diketahui oleh pihak perusahaan dengan melihat keluhan yang dilampirkan pengguna jalan tol 
di formuli CPAR.

Berdasarkan penelitian yang berjudul peran public relations dalam menjalankan pengendalian mutu perusahaan studi kasus PT. Jalan Tol Lingkarluar Jakarta, dapat dilihat bahwa peran public relations yang diwadahi oleh manajemen representative sangatlah berperan penting dalam melakukan proses pengendalian mutu perusahaan, dapat terlihat dari penjelasan yang diberikan terhadap peneliti mengenai proses cara kerja pengendalian mutu, motif dan achievement apa saja yang didapat boleh karyawan hingga membahas seberapa besar tanggung jawab public relations internal dalam menangani proses pengendalian mutu perusahaan. Upaya ini juga merupakan tujuan dari public relations berupa fungsi manajemen yang dilakukan melalui berbagai macam program penegendalian mutu dan kegiatan-kegiatan yang benar-benar terencana demi membina hubungan baik serta mencapai berbagai tujuan perushaan.

\section{SIMPULAN}

Berdasarkan uraian penelitian serta pembahasan yang peneliti lakukan terhadap PT. Jalan Tol Lingkarluar Jakarta dengan judul peran public relations internal dalam pengendalian mutu perusahaan studi kasus PT. Jalan Tol Lingkarluar Jakarta. Maka peneliti dapat menarik kesimpulan dari hasil penelitian yang akan didapatkan dari sumber data primer yang didalamnya key informan dan informan, juga didukung dengan data sekunder untuk meningkatkan kualitas data adalah sebagai berikut: Dalam program kegiatan pengendalian mutu perusahaan manajemen representative membuat perencanaan rapat kerja supaya memudahkan devisi-devisi terkait untuk menargetkan proses kerja disetiap devisinya. Perencanaan jadwal dibagi menjadi 3 bagian diantaranya dalam waktu satu bulan, persemeseter dan tahunan. Disetiap bagian waktunya memiliki fungsi yang berbeda-beda. Perencanaan jadwal proses kegiatan pengendalian mutu juga dibuat oleh disetiap devisinya. Perencanaan yang mempunyai fungsi yang sama dengan devisi manajemen representative yaitu supaya memiliki target waktu untuk mennyelesaikan proses pengendalian mutu perusahaan. Selain itu PT Jalan Tol Lingkarluar Jakarta mendaftarkan perusahaan ke kompetisi tingkat nasional yang bertujuan untuk mendapatkan penghargaan dan sertifikat dai kompetisi tersebut.

Motif yang dimiliki oleh manajemen representative adalah mempunyai rasa kepedulian terhadap citra dan reputasi perusahaan. Citra dan reputasi perusahaan dapati dilihat dari tingkat kepuasan pengguna jalan tol. Tingkat kepuasan pengguna jalan tol dapat dilihat dari form CPAR dan web perusahaan yang sudah disediakan oleh PT Jalan Tol Lingkarluar Jakarta, selain itu achievement yang didapat peserta atau karyawan dari kegiatan proses pengendallian mutu adalah apabila proses pengendalian mutu itu berhasil dan mendapatkan penghargaan dari kompetisi karya mutu tingkat nasional maka karyawan berhak mendapatkan promosi untuk naik jabatan dan mendapatkan uang yang cukup besar.

Tanggung jawab yang dimiliki oleh manajemen representative adalah tanggung jawab yang besar. Karena apabila dari proses pengendalian mutu itu tidak berjalan atau tidak berhasil maka sepenuhnyatelah menjadi wadah terhadap devisi-devisi terkait untuk menjalankan proses pengendalian mutu perusahaan. Tanggung jawab yang besar juga dimiliki oleh setiap devisi-devisi terkait. Karena apabila ide-ide yang dikeluarkan tidak meningkatkan kepuasan pengguna jalan tol maka akan berdampak kepada citra danreputasi perusahaan.

\section{DAFTAR PUSTAKA}

Ardianto, Elvinaro. 2014. Metode Penelitian Public Relations. Bandung (ID): Rosdakarya Krisyantotno, Rahmat. 2014. Riset komunikasi. Jakarta (ID): Kencana Prenada Media Grup. Danandjaja. 2011. Peranan Humas Dalam Perusahaan. Yogyakarta (ID): Graha Ilmu.

Ruslan, Rosadi. 2008. Manajemen Public Relations \& Media Komunikasi: Jakarta (ID): PT Raja Grafindo Persada

Soemirat dan Ardianto. 2010. Dasar-Dasar Public Relations. Bandung (ID): PT Remaja Rosadakarya. 
Morissan, 2008. Manajemen Public Relations, Strategi Menjadi Humas Profesional. Jakarta (ID): Kencana Prenada Media Group.

Moleong, Lexy J. 2011. Metode Penelitian Kualitatif. Bandung (ID): PT Remaja Rosdakarya.

Moleong, Lexy J. 2014. Metode Penelitian Kualitatif. Edisi Revisi. Bandung: PT Remaja Rosdakarya.

Daymon, Christine danlmmy Holloway. 2008. Riset Kualitatif. Bandung (ID): Bentang.

Butterick, Keith. 2012. Pengantar Public Relations : Teori dan Praktik. Jakarta (ID): PT Raja Grafindo Persada.

Cecelia S. Kilian. 2005. The world of W.Edwards Deming. Quality Control. Bandung (ID): Bentang Robert K Yin. 